\title{
Ethical issues raised by the new orientations in ergonomics and living labs
}

\author{
Javier Barcenilla ${ }^{\mathrm{a}, *}$ and Charles Tijus ${ }^{\mathrm{b}}$ \\ ${ }^{\mathrm{a}} 2$ LP (EA 4432), Expériences utilisateurs dans le Traitement des Interactions technologiques et des Conduites \\ humaines et sociales - Université Paul Verlaine - Metz, Ille du Saulcy, 57045 Metz, France \\ ${ }^{\mathrm{b}}$ CHArt - LUTIN, Laboratoire "Cognitions Humaine et Artificielle", Cité des Sciences et de l'Industrie - 30 \\ avenue Corentin Cariou, 75019 Paris, France
}

\begin{abstract}
User Experience Theory (UXT) provides us with criteria for designing products and technical systems for everyday activities (playing, learning, working, ... ) so as to satisfy users. Living Labs (LL), are plateforms used for the design and evaluation of technical systems. As such, they constitute tools that bring to this process some constraints., However these constraints have to be articulated to the UXT. In other words, UXT should specify the place, the role and function LL should play in the design of new products, how it should contribute to satisfying UX, and how the methods and techniques should be conceived or borrowed from other disciplines. UXT also raises ethical issues: impartiality (independent, public, replicable) of research models in the context of economical constraints (dependant, private, secret prototypes) and of industrial pressure, the use of intrusive and persuasive techniques, even with the prior informed consent of participants, ergo-marketing, deontology codes, the use of specific participants, belonging of an UX innovative solution, confidentiality with ICT, and so on. Because the UX, as well as LL literature, have shown little concerns for ethical considerations, till now, we define LL-UX ethical issues as a new research topic, and we list a number of problems to be solved in order to have an ethical LL-UX methodology for open innovation.
\end{abstract}

Keywords: Ergonomics, Ethics, Living Labs, User Experience, Open Innovation

\footnotetext{
*Corresponding author. E-mail: barcenilla@univ-metz.fr.
} 


\section{Introduction}

"Open innovation is a paradigm that assumes that firms can and should use external ideas as well as internal ideas, and internal and external paths to market, as the firms look to advance their technology" [8]. In a certain way, open innovation is a kind of propective ergonomics in the sens that it contributes to the identification of future systems and products, their use and the impact of the solution retained.

As a scintific discipline, ergonomics is evolving, and thus its theotical substrate, its methologies and as a conséquence its codes of conduct.

Ethics may be defined as a whole set of complementary rules, that defines a profession and its codes of conduct (e.g., ergonomics research or practice) by constraining the activities of the professionals (e.g. running ergonomic observations). If there is the emergence of a profession or of a kind of activities, then there is a need for a set of ethics rules. Note that there is a close link between the ethic rules on how to run an activity and the activity itself. For instance, if there is an ethic rule on the "prior and informed consent" of participants, it means that if we are enrolling persons to participate in some activities their consent is mandatory and prior to the requested activity. The whole set of ethic rules of how to conduct an activity determines the "how it works" of the activity.

The present paper is about how to proceed to generate a set of ethic rules that should organize the ergonomic activity while running open innovation processes based on User Experience theory (UXT), in the setting of Living Lab (LL). The problem of having the required set of rules is not solved in the paper. The paper is more about expressing the ethical dimensions to consider for an appropriate set of rules, as well as how to proceed to generate the ethics of open innovation activities, precisely by using a LL approach.

\section{The dimensions of ethics}

Organizations of professionals are publishing the codes of ethics for their members. The persons who write such codes of ethics are representatives of the members of the professional organizations.

There are several dimensions of ethics. A first and top level dimension is general. For instance, because Ergonomics is "the study of human abilities and characteristics which affect the design of equipment, systems, and jobs and its aims are to improve efficiency, safety, and well being”, some general rules might concern the dignity of mankind, or consequences to society as a whole $[9,18]$. Because Ergonomics is also "a body of knowledge about human abilities, human limitations and other human characteristics that are relevant to design" [7], another general rules will concern the respect of individuals, cultural and role differences, including (but not exclusively) those involving age, disability, education, ethnicity, etc. There are finally general rules about the rules, such as "Be willing to explain the bases for ethical decision making, expressing clear ethical principles, values and standards".

An intermediate dimension of ethics concerns the professional conduct, such as "must express and demonstrate commitment to competence, and maintain the integrity of the moral and collegial nature of the ergonomics profession; must be accountable for one's conduct to the profession, exhibit altruism; no economic or personal interests in the project or results, etc".

Finally, the more specific dimensions are about the activities themselves. For instance, among ethical issues related to ergonomics studies, some researchers [24] include 'Participants' right to decide whether they want to participate or not and have a right of withdrawal, Informed consent and right to know: Everyone has the right to know about the possible risks in the project. Results are published so that all can get to know about them. Personal information is confidential, non-maleficience: no participants should suffer from the project's maleficience. The aim of the project should be to improve conditions for the participants".

\section{New orientations in Living Labs and Ergonomics}

Ergonomics is changing. From being " a body of knowledge about human abilities, human limitations and other human characteristics" [3, 7], or "the study of human abilities and characteristics which affect the design" [4, 9], ergonomics turns to be UXcentered design, placing the user at the centre of the this process and taking into account his habits, backgroung and préférences [30].

Based on UX, Ergonomics is part of the Living Lab methodology, which involves a network of real people with rich experiences. This is a new way of dealing with community-driven innovation for sensing, prototyping, validating and refining complex solutions in multiple and evolving real-life contexts [20]. In addition to users, LL methodology involves 
researchers and product developers to achieve a deep understanding and uncover valuable insights about how user interact with products that bring real benefits to consumers and have a chance of succeeding in the market [11].

Thus, UX in LL is much more than cooperative or participatory design with the inclusion of users within a development team [6]. In LL methodology for open innovation (R\&D\&I: Research \& Development \& Innovation), citizens, developers and researchers do co-operate for Ergonomics, defined as designing for human use, for turning human machine antagonism into human-machine synergy [14].

Such new orientations in Ergonomics and Living Labs deserve a specific UX theory as well as a dedicated code of ethics.

\subsection{Living Labs Methodology}

LL methodology is bringing together SMEs, Citizens and other End Users (Public bodies and institutions) to analyze users needs, assess the acceptability of new technologies or prototypes and evaluate the impact of new technologies on users behavior.

According to Eriksson et al. [11], Living Labs provide infrastructures for observing the response of humans to an innovation: experimental Living Labs extend traditional technology-centric R\&D depart- ments by giving them instruments for researching human and social issues affecting innovation (R\&D\&I).

Vandi, Tijus et Baccino [29] analyzed the links between citizens (users), scientists (researchers) and industrials (PMEs), in traditional Research Studies, in Social Studies, in R\&D Studies and in Living Lab Studies. Figure 1 shows how roles and demans change as a function of differents research settings. With traditional laboratory studies, the researcher is asking the industrial to build some scientific devices and is asking the citizen to participate in experiments. In social studies, as the needs for knowledge come from the society, in a certain way citizens are asking researchers to evaluate the impacts of industrial devices on citizens. In classical ergonomics, $R \& D$, it is the industrial who is asking the researcher to test his device by having citizens as users. In Living Lab studies, the situation is more complex since the citizens want to participate, have their own hypothèses, and request solutions from the researcher and from the industrial. The industrial wants to know both from citizens and the scientists, while the researchers want to help the industrials by informing them about the behavior and the thinking of the citizens as users.

This tri-part operation through LL provides some advantages for the UX theory.

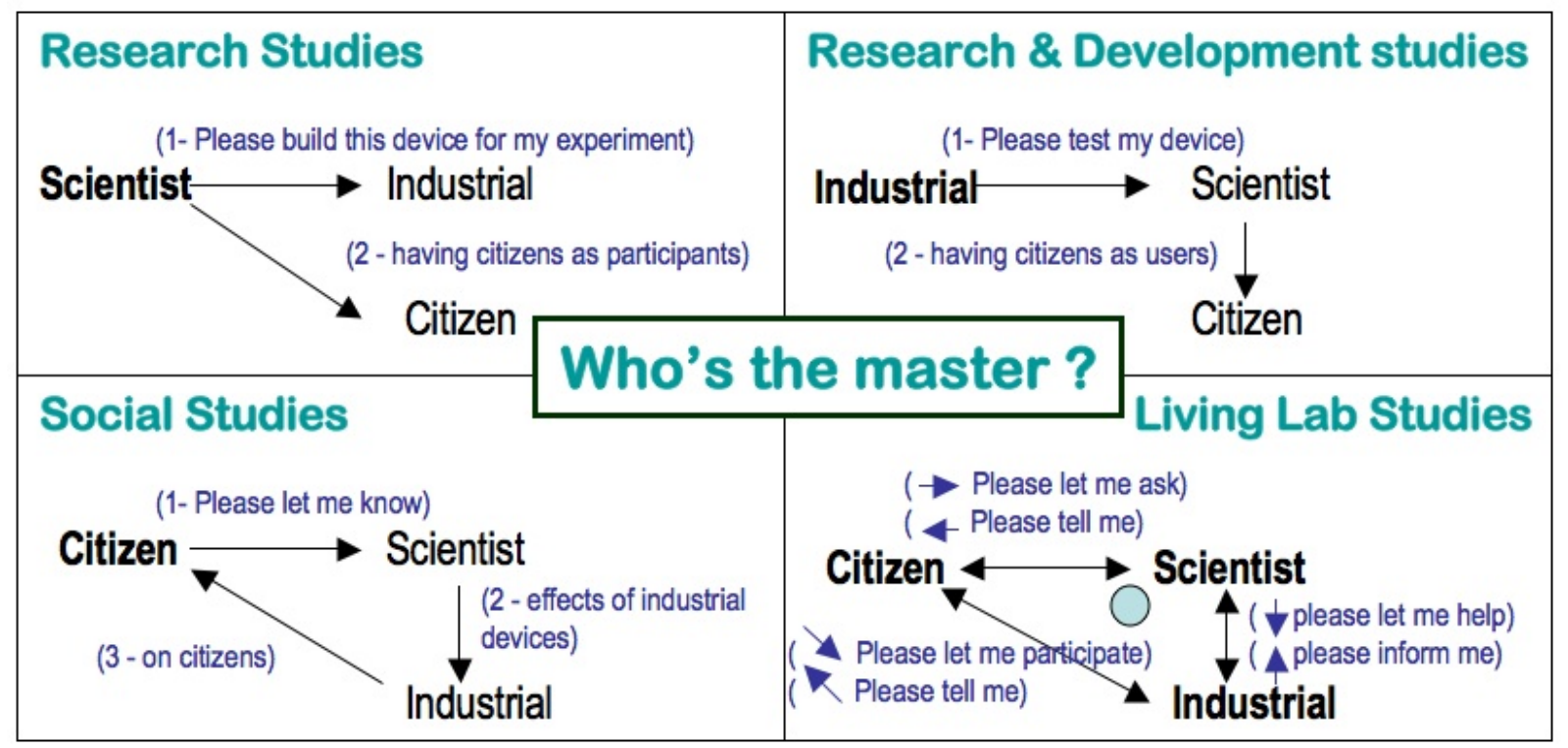

Fig.1. How citizens (users), scientists (researchers) and industrials (PMEs) relate in traditional Research Studies, Social Studies, Research \& Development Studies and Living Lab Studies. From Vandi, Tijus \& Baccino [29] 


\subsection{A UX Theory based on LL methodology}

In the line with Kuorinka [17], we define Ergonomics as having three components: (i) the analysis of the situation that requires a technological solution; (ii) the design of a technological solution; and (iii) the empirical testing of the design solution. The UXcentred approach for these three elements has been established $[6,13]$. It can be differently justified.

A first way of justifiyng the adoption of a UXcentred approach is the "do-it-yourself" social change with the development of accessible and flexible technologies, which allows more design choices, customization, and specification options [30]. The "do-ityourself" approach can be clearly identified with FabLab devices that can be tailored to individual needs in ways that are not practical or economical with mass production. In that case, the user is the developer.

Another justification is that developers have to generate solutions that place users in a central role. In a participatory design approach, users are actively involved in the design process. They are co-designers in the development of the products. It is because the product is for the user that the developer is asking the user what $\mathrm{s} / \mathrm{he}$ wants.

Differently, our point of vue is that we must adopt a user-centred approach for fulfilling the userdeveloper gap. Our proposal is based on the distinction between, on the one hand, the logic of functioning (or the prescribed task), and on the other hand, the logic of use (or the effective task). This is a useful distinction in the different domains where a technical device is used $[23,25,28,12]$. Note that this justification encompasses the two others since both the "do-it-yourself" or "co-designing" must fill the userdeveloper gap.

When using a device to accomplish a task, people are acting on the device. The user actions are commands and procedures for hidden functions that provide results that are intended to solve the tasks. Filling the user-developer gap is bridging actions (user) to functions (developer) and bridging results (developer) to task (user). The UX theory and methodology is not simply acquiring the knowledge of the "howto-do it" of the user, to be transformed into the "howto design it" of the developer. The UX theory is also to acquiring the knowledge of the "how-to design it" of the developer, to be transformed into the "how-todo it" of the user. We assume UX to be misleading if it does not include the function level. The specificity of the Living Labs methodology is the tri-part cooperation, about task and function, about actions and results. This is this methodology that could provide "the participatory, cooperative, and sustainable information society in which knowledge and technology are together in such ways that humans interact in mutually benefiting ways" [13].

\section{Ethical issues}

UX-centred Living Labs are bringing together SMEs, Citizens and researchers to analyze situations requiring technological solutions for users needs, to design solutions, to assess the acceptability and usability of technological solutions, and to evaluate their impact on users behavior. The ethical issues that emerge in these ergonomics activities will be the topics of the following sections.

\subsection{Playing the UX-LL game}

A first ethical challenge is the tri-part cooperation: it needs trust in co-operation from each part according to adequation of the design to use. Users may ask for the impossible. Developers can refuse possible user's design. Researchers might not bridge the user-developer gap, so as to favor cooperation, to overcome motivational and cognitive barriers that manifest themselves when researchers have different expertise, scientific discipline or practical backgrounds [10].

Each part has to play the game. Adapting Asimov's laws of robotics, with its meta-level third rule, might be LL ethical principles:

the design for which Users were cooperating, through inaction, let users being disappointed,

the design must fit user needs, except where such design would conflict with the first rule, and finally,

- $\quad$ the design must be as good as possible as long as such design does not conflict with the first or second rule.

If we agree with the participative rules, then there are subsequent challenging ethic issues.

\subsection{Informing users about industrial innovations}

An ordinary ethical rule is to debrief research participants at the conclusion of their participation, in 
order to inform them of the outcomes and nature of the research.

With UX Living Lab methodology if would be suitable and more important to trasmit knowledge about the research prior to the study. For the industry, co-operation in Living Lab open innovation is a process of opening the boundaries of the industry to share and exchange knowledge and information [8]. Although using users' knowledge increases speed, efficiency and effectiveness of innovation process, users might also have the knowledge of invention, or at least of innovative ideas. However, NonDisclosure Agreement (NDA) is difficult to solve with a large amount of users.

\subsection{Informing users that they have the right to withdraw at any time}

UX Living Lab methodology involves users participation. User engagement is related to the quantity and quality of his contribution and investment [13]. However, note that another ordinary ethic rule is to inform research participants from the first contact that their right to withdraw at any time is not affected by the receipt or the offer of any financial compensation or other inducements for participation. Each Living Lab member should freely decides whether they wish or not to continue participating. Thus, we have contradictory rules that need to be solved.

According to Hersh [15], users should be informed of "the desired involvement and associated time commitment; whether expenses or payment will be available; any training that is provided; the benefits to the specific person, as well as more generally, the time span these benefits will occur over." Hersh underlines a very important Living Lab ethic rule about testing a particular device: participants should be informed whether they will be able or not to continue to use the device after the end of the study period. Users can be disappointed if they have to stop using the device after the end of the study period, specifically if device has been integrated within their daily life.

\subsection{The belonging of an innovative solution provided by an $U X$}

Other ordinary ethic rules are (i) to respect the knowledge, insight, experience and expertise of participants and of the general public, and (ii) to avoid practices that are unfair or prejudicial. If the first rule is coherent with Living Lab methodologies, the second rule is challenging.

According to Bruns [5], open innovation benefits from the creativity of the participators for commercial gains. As users become a source of ideas and innovations, there should be appropriate rewarding. As a consequence, there should be some kind of contract between users and industry.

There is also a copyright problem. In relation to copyright, the World Trade Organisation's Agreement on Trade-Related Aspects of Intellectual Property Rights (TRPIS) [31] states that protection shall extend to expressions and not only to ideas, procedures, methods of operation or mathematical concepts as such. TRIPS force Members to protect industrial designs expressions that are new or original. Given that users may frequently make very precise expressions (drawings, etc.), the ethics is challenging.

As a matter of fact, literature on Living Labs practices [2, 26, 22, 27] has given little attention to users' financial compensation. According to Mulder et al. [20], Living Labs "seem to operate with the implicit assumption that users are unpaid contributors, motivated by the anticipation that their participation will solve their problems or lead to 'better' designs."

\subsection{The confidentiality of user's data}

A related ethics issue is about the nature of the collected data and their privacy. The corresponding usual ethics rule is to make audio, video or photographic recordings of participants only with their explicit permission, when they are are considered legally competent, or otherwise whith the permission of duly authorized representatives.

The options of anonymous data, as whether or not respondents want to be named or remain anonymous, are open challenging questions.

Storing users data should be transparent: information given to users is to be explicit and clear about which personal data are or will be stored. At the same time, we should give autonomy to the user in deciding which personal data s/he wants to have stored, publicly or semipublicly displayed, or transmitted to others [13].

But, what to do with the users' genius ideas that they do not want to share? 


\subsection{Assistive open Innovation for particular care}

People with impairments are particularly welcomed as users for assistive open innovation. They should be participating in Living Lab research, being volunteers, as much as possible because of their useful contribution [19, 15]. The preceding ethics rules are then highly important. Among them, ensuring that impaired users are given ample opportunity to understand the nature, purpose, and anticipated consequences of their Living Lab participation.

However, because the open innovation process is about the future of things, and because impaired users really need the technology, how do we deal with innovation processes that make users being disappointed? Because of the cognitive and motivational barriers that could be difficult to overcome, and finally the user-developer gap, a disappointing technology might indicate that their interests are over-looked.

\subsection{The use of cognitive persuasive technologies}

While participating in the tri-part cooperation LL methodology, the Ergonomics researcher or professional might use some persuasive technics, such as Wizard of Oz thus making users believe that the innovation is on the shelf being ready for use.

According to Nemery, Brangier et Kopp [21] persuasion technology aims at influencing and persuading people. Thus, those technologies raise important ethical questions. They propose 8 ethical principles for persuasive design:

- Persuasive technology results should never be considered unethical if the result would have occurred regardless of persuasion.

- The motivations behind the creation of a persuasive technology must remain ethical.

- Persuasive technology should take responsibility for all results reasonably in its foreseeable use.

- Persuasive technology should ensure that it considers the privacy of users.

- A technological persuasion that relays personal information about a user to a third party must be subject to scrutiny.

- Persuasive technology should disclose their motivations, methods and expected results, unless such disclosure would seriously undermine another objective ethics.

- Persuasion technology does not deceive in order to achieve a final persuasion not avowed or undeclared.
- Persuasive technology should never seek to persuade people to do something they would not consent themselves to be persuaded to do.

\section{Conclusion}

We just have pointed out the major questions raised by new development on innovation with products and services based principaly on UX theory and LL methodolgy. However, there are others Ethics issues. For instance, difficulty of involving large sample of users; questions raised about research in ergo-marketing (is ergonomics assuming its function while contributing to consumers matters that are far away from ergonomics concerns?), etc. Although professionals and researchers have codes of ethics, what about others (marketing, computer science, engineers, etc.)? What about deontology codes of users

To conclude, defining UX-Living Labs activities is to have an adapted tri-part code of ethics and that, should be part of the Living Lab methodology.

\section{References}

[1] Arscott, K., Dagnan, D., \& Kroese, B.S. (1998). Consent to psychological research by people with an intellectual disability. Journal of Applied Research in Intellectual Disabilities, 11, 1, 77-83.

[2] Ballon, P., Pierson, J., \& Delaere, S. (2005). Test and experimentation platforms for broadband innovation. Proceedings of 16th European Regional Conference by the International Telecommunications Society (ITS), Porto, Portugal.

[3] Bartlett, F.C. (1962). The Future for Ergonomics (Ergonomics Research Society Lecture April 1962). Ergonomics, Volume 5, Number 4.

[4] Brookhuis, K.A. (2008). From ergonauts to infonauts: 50 years of ergonomics research. Ergonomics, 51, 1, 55-58.

[5] Bruns, A. (2007). Produsage: Towards a Broader Framework for User-Led Content Creation. Proceedings of the 6th ACM SIGCHI Conference on Creativity and Cognition, Washington, DC, June 13-15.

[6] Carroll, J. M., Chin, G., Rosson, M. B., \& Neale, D. C. (2002). The development of cooperation: Five years of participatory design in the virtual school. In J. M. Carroll (Ed.), Humancomputer interaction in the new millennium (pp. 373-395). Boston: ACM Press.

[7] Chapanis, A, (1990). The International Ergonomics Association: its first 30 years. Ergonomics, 33, 3, 275 - 282.

[8] Chesbrough, H.W. (2003) Open Innovation: The New Imperative for Creating And Profiting from Technology. Boston: Harvard Business School Press.

[9] Corlett, E.N. (2000). Ergonomics and ethics in a changing society Applied Ergonomics, 31, 679-683.

[10]Dutilleul, B., Birrer, F.A.J., \& Mensink, W. (2010). Central European Journal of Public Policy, 4, 1, 60-85 
[11]Eriksson, M., Niitamo, V-P. \& Kulkki, S. (2005). State of the art in utilizing Living Labs approach to user-centric ICT innovation. Lulea University of Technology.

[12]Flynn, D. J., \& Jazi, M. D. (1998). Constructing User Requirements: A Social Process for a Social Context Information. Systems Journal, 8, 53-83.

[13]Fuchs, C., \& Obrist, M. (2010). HCI and society: Towards a typology of universal design principles. International Journal of Human-Computer Interaction, 26, 6, 638-656.

[14] Galley, M. (1999). 50 Years of Ergonomics - Where have we been and where are we going ? Ergonomics in more modern times. Society, 1-13.

[15]Hersh, M.A. (2010). The design and evaluation of assistive technology products and devices, Part 1: Design. In Blouin, M. \& Stone, J. (eds.), International Encyclopedia of Rehabilitation. CIRRIE.

[16]Kallman, E.A. \& Grillo, J.P. (1996). Ethical decision making and information technology (2nd ed.). Boston, Massachusetts: Irwin/McGraw-Hill.

[17]Kuorinka, I. (2000). History of the International Ergonomics Association: The first quarter of a century. Geneva: IEA Press.

[18] Mason, R.O. (1986). Four ethical issues of the information age. Management Information Systems Quarterly, 10, 1, 5-12.

[19] Milliken, A.D. (1993). The need for research and ethical safeguards in special populations. Canadian Journal of Psychiatry, 38, 681-685.

[20]Mulder, I., Velthausz, D., \& Kriens, M. (2008). Living Methodologies: Understanding the Dynamics of Innovation. In Schumacher, J. \& Niitano, V-P. (eds.). European Living Labs - a new approach for human centric regional innovation (pp. 31-38). Berlin: Wissenschaftlicher Verlag.

[21]Nemery, A., Brangier, E., \& Kopp, S. (2009). How cognitive ergonomics can deal with the problem of persuasive interfaces. In L. Norros, H., Koskinen, L. Salo \& P. Savioja (Eds.), Designing beyond the product: understanding activity and user experience in ubiquitous environments (pp. 61,64) ECCE'2009, European Conference on Cognitive Ergonomics.

[22]Niitamo, V-P., Kulkii, S., Eriksson, M., \& Hribernik, K.A. (2006). State of the art and good practice in the Field of Living Labs. Proceedings of the 12th International Conference on Concurrent Enterprising: Innovative Products and Services through Collaborative Networks, 341-348

[23] Norman, D.A. (1983) Some observation on mental models. In Gentner D. \& Stevens A.L. (Eds.), Mental Models (pp. 7-14). Hillsdale N.J: Lawrence Erlbaum Associates.

[24]Olsen, K. B, \& Legg, S. (2004). Ethics in ergonomics - experience from the Nordic Ergonomics Societies. 36th Annual Conference on Working life Ethics. NES2004, Denmark.

[25] Richard, J. F. (1983). Logique du fonctionnement et logique de l'utilisation. Rapport de recherche INRIA N ${ }^{\circ} 202$

[26] Schumacher, J. \& Niitano, V-P. (eds.) (2008). European Living Labs - a new approach for human centric regional innovation. Berlin: Wissenschaftlicher Verlag Berlin.

[27] Ståhlbröst, A., Annika Sällström, A., \& Holst, M. (2009). User Evaluations in the Wild - Experiences from Mobile Living Labs. Mobile Living Labs 09: Methods and Tools for Evaluation in the Wild, Bonn, Germany, 7-10,

[28] Tijus, C., Poitrenaud, S., \& Barcenilla, J. (1997). Semantics Networks of Action for Conception and Evaluation of Interfaces. Revue Internationale de Systémique, 11, 95-107

[29] Vandi, C., Tijus, C., \& Baccino, T. (2010). Serving three Masters: Citizen, Industrial and Scientific: a case study. Living Labs Summer School 2010 on Collaborative Innovation through Living Labs, 22-27th August, LUTIN, universcience, Cité des Sciences et de l'Industrie, France
[30] Woolley, M. (2004). Beyond design? - patterns of time and use in sustainable innovation. Seminar on Signification, Usability, and Interaction in Design, University of Art and Design, Helsinki, Finland

[31] World Trade Organisation (und.) Overview: the TRIPS Agreement: a more detailed overview of the TRIPS Agreement. www.wto.org/english/tratop_e/trips_e/intel2 e.htm 